\title{
SPECIAL EXERCISES ACCORDING TO DYNAFOOT DATA AND ITS EFFECT ON THE PROJECTED FORCE INDEX AND THE PERFORMANCE OF THE STRAIGHT FORWARD AIRWAY SKILL ON THE GROUND MOVEMENTS MAT
}

\author{
Doaa Awad Atwan Shukuri, Prof.Dr. Bushra Kazim Abdul-Redha Al-Hamashi \\ University of Baghdad / College of Physical Education and Sports Sciences for Girls
}

DOI: $10.37648 /$ ijrssh.v10i01.047

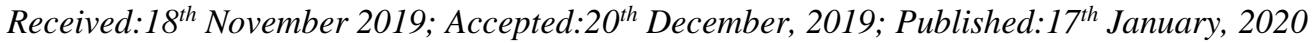

\section{ABSTRACT:}

The emergence of electronic technology in the world and training techniques made researchers put their hands on what was produced by this technological revolution, subjecting the movements of technical gymnastics to advanced devices and kinetic analysis laboratories, including the dinafoot device that simulates the actual performance of skills by giving accurate kinetic indicators where it gives corrections about pressure areas that are exposed It has the foot and the ruler on the surface of the earth, as it gives data for the corners of the foot during the steps of walking or running and measuring the force applied to the feet at each step. As for the research problem, the skill in question needs the longest flight time as well as the highest possible height for aesthetic performance and the smooth flow of movement in full form. The researcher found that there is a weakness in the force on the rug the moment when the front air skill starts, which forces the player to perform the skill incorrectly or expose them Several class discounts due to low performance.

The third chapter included the research community and sample, as the community of the research sample reached (4) players, Jomna Six, and the researcher chose his sample in an intentional way, and they are players in the Future Youth Forum in Maysan for young men. As for the fourth chapter, the results are presented, analyzed, and discussed. The fifth chapter includes conclusions and recommendations, including:

- Adopting modern techniques when analyzing a specific skill in gymnastics objectively to reveal strengths and weaknesses.

- The results showed the effectiveness of using exercises related to the skillful performance of the forward anterior airway.

\section{INTRODUCTION}

The emergence of electronic technology in the world and training techniques made researchers put their hands on what was produced by this technological revolution, subjecting the movements of technical gymnastics to advanced devices and kinetic analysis laboratories, including the dinafoot device that simulates the actual performance of skills by giving accurate kinetic indicators where it gives corrections 
about pressure areas that are exposed It has a foot and is dominated on the surface of the earth. It also gives data for the corners of the foot during the steps of walking or running and measuring the force applied to the feet at each step, in addition to analyzing the kinetic performance of the skills by adopting kinematic analyzes, and this is done simultaneously. With video shooting using the latest software, which has an effective and effective role.

As the ground movements carpet device is an essential and important device for the training base, as some of the skills that lead to it are the basis for many skills on other devices, and there are also special requirements skills that are part of the motor chain, which includes the anterior, posterior, and lateral open and open air core (straight). With or without winding on the longitudinal axis.

It is noticeable that the skills of the various types of aerodynamics on the ground movement rug system are characterized by the distribution of force on the foot, which is the main feature of all motor skills. As without the distribution of strength, the goal of the movement (its beauty, grace and artistic aspects) cannot be achieved.

:Research problem

The skill in question needs the longest flight time as well as the highest possible height for aesthetic performance and the smooth flow of movement in full form. The researcher found there was a weakness in the power on the rug the moment the beginning of the forward airway skill begins, forcing the player to perform the skill incorrectly or subject them to several discounts in The score is a result of low-performance performance.

Hence, the researcher wanted to study this problem and put scientific and practical solutions and treatments through the adoption of some biomechanical variables by developing exercises as an attempt to solve this problem.

:Research Objectives

- Identify the projected force variable according to the data of the Dynafoot device and the level of performance of the forward straight-core airway skill on the ground movement mat device.

- Preparing special exercises according to the Dynafoot data presented and the stages of performance.

- Knowing the effect of special exercises on the controlling force and the level of performance of the straight forward airway skill on the ground movements mat.

:Research imposition

- There are no statistically significant differences between the pre and post tests in the projected force index and the performance of the skill of the straight forward airway.

:areas of research

- The human sphere: emerging gymnasts (Future Youth Forum) in Maysan, ages (10-15) years.

.- Timeframe: $2 / 8 / 2019$ to $22 / 10 / 2019$

.Spatial domain: The Gymnastic Hall in Maysan Governorate-

\section{MATERIALS AND METHODS:}

\section{Research Methodology:}

There are many approaches used in scientific research, the researcher used the experimental approach to design a single group to suit the nature of the problem and the research community.

\section{Search community and sample:}

The research sample included the players of the Future Youth Forum in Maysan for young athletes, ages (10$15)$ years, and they were chosen in a deliberate manner, and the number (4) is young players. As the sample represented the research community $100 \%$.

\section{Means of gathering information, tools and devices used in research:}

Means of collecting information:

- Arab and foreign sources

Information Network (Internet) -

- Data dump form

- The opinions of experts and specialists

:Devices and tools used

-- Dynafoot device

.- HP Electronic Calculator

Dinah Foot.-

The Dinafoot device has been used and it is one of the modern and advanced devices that are placed under the foot as it gives us the amount of mechanical distribution of pressure and strength in addition to other Kinematic and kinetic parameters related to the balance of the feet and the difference between them as well as the footprint 
and pressure that the parts of the feet place, whether the heel or the combs or the right side or side Left.

This device is placed in the athletic shoe by means of a tank under the foot and receives information through sensors inside the device (15) sensor and bluetooth system connected to the computer. It works to copy an image of the entire foot and store it inside the memory in the device and display it on the computer after the athlete has made a physical effort.

\section{Field research procedures:}

Determination of biomechanical variables :

The projected force is chosen as a biomechanical indicator that is extracted from the Dynafoot device.

\section{:Exploration Experience}

The researcher conducted an exploratory experiment to find out the suitability of the exercises and the appropriateness of the devices for the research eye to find out the pros and cons that accompany the main experiment.

:The first exploratory experience

- Make sure the performance of the Dinafoot device is valid

Verify the location of the test and its suitability for carrying out the tests -

Knowing the time required for carrying out the tests -

The Second Exploratory Experience Exercises concerning the Power of Power:

- Repeat the maximum performance of the players and the time it takes to perform the exercise

The suitability of exercises for the sample level

\section{:Main experience}

Tribal tests

Tribal tests were conducted on the research sample on (2/8/2019) on Friday in the hall of the Future Youth Forum in Maysan

:Preparing the training exercises
- The researcher adopted skilled physical exercises for the youth in the youth after reviewing the scientific resources and electronic and video programs, which helped the researcher collect a set of skillful physical exercises related to the skill of the straight air on the ground floor mat device for the beginners

- The exercises were presented to a group of experts and specialists in the field of training and the field of gymnastics, where the time taken for each exercise was determined during the exploratory experiment, and in the light of it the frequencies will be determined in each training unit.

- The researcher adopted the training method with repetitions in the application of exercises and gradually from easy to difficult and in a manner appropriate to the capabilities of the research sample

The training program consisted of (15) units with three training units per week during the days (Sunday Tuesday - Thursday)

- The program duration is two months, and the training unit time per week is (105) minutes. The time taken in the main part is (60) minutes in the training unit.

- The researcher used the method of training the high intensity and low intensity according to the requirements of the muscles working on the foot (the dominant force).

The exercises were organized in the main part in the form of three training units on the principle of (2: 1), i.e. one week of low intensity and two weeks of high intensity.

:Dimensional search tests

After completing the application of the special exercises, the researcher conducted the post-test within the same procedures of the pre-test and under the same conditions.

\section{:Statistical means}

The appropriate statistical methods will be used by applying the spss program 


\section{RESULT AND DISCUSSION:}

Presentation, analysis and discussion of the research results:

Table (1)

Shows the pre and post biomechanical variables of the mean, the standard error of differences and the value (t) of the research sample

\begin{tabular}{|c|c|c|c|c|c|c|c|c|}
\hline \multirow{2}{*}{$\begin{array}{l}\text { Significa } \\
\text { nce }\end{array}$} & \multirow[t]{2}{*}{ SIG } & \multirow{2}{*}{$\begin{array}{l}\text { Calculated } \quad \mathrm{T} \\
\text { value }\end{array}$} & \multicolumn{2}{|l|}{ Post-test } & \multicolumn{2}{|l|}{ Pre-test } & \multirow[t]{2}{*}{ measruing unit } & \multirow[t]{2}{*}{ Variables } \\
\hline & & & $\begin{array}{l}\text { standard } \\
\text { deviation }\end{array}$ & $\begin{array}{l}\text { Arithmetic } \\
\text { mean }\end{array}$ & $\begin{array}{l}\text { standard } \\
\text { deviation }\end{array}$ & $\begin{array}{l}\text { Arithmetic } \\
\text { mean }\end{array}$ & & \\
\hline moral & 0.031 & 21.322 & 412 & 1728 & 322 & 1668.000 & Net & $\begin{array}{l}\text { The power } \\
\text { placed on the } \\
\text { dinafoot }\end{array}$ \\
\hline moral & 0.001 & 33.327 & 0.724 & 6.645 & 0.523 & 2.750 & Degree & $\begin{array}{l}\text { Perform } \\
\text { straight } \\
\text { forward } \\
\text { airway skill }\end{array}$ \\
\hline
\end{tabular}

In the indicator of the dominant force at the moment of rise, the differences were of significant significance between the pre and post tests and in favor of the post tests, and this is an important indication of the development of the force and its investment well during the advancement among the individuals of the research sample as a result of the exercises that were developed by the researcher using exercises that bear the nature of jump over obstacles Pleomatra exercises, and that the level of performance achieved by the members of the research sample for such values of the dominant force during the advancement was supposed to be higher, but it may be attributed to other reasons, for example not to employ this force by taking inappropriate conditions for the advancement to direct the path Rki towards the goal of the movement to overcome the moments, which is supposed to reach a good position to perform the skill of aerodynamic summersault straight, came this conclusion to the verification of the values of strength by Allowathbyn weights inflicted with a rate $(62.43$ $\mathrm{kg})$.

As well as the level of skill assessment, a significant degree was achieved in the distance tests as a result of the evolution of the rate of jump in the tribal from the CONCLUSIONS:

Through the results, the researcher reached the following conclusions: post-way, as it was emphasized in the exercises prepared according to the percentage of contribution to interest in exercises with dual structure, which was similar to performance and its goal is to develop the status of raising the speed required to place the foot up using auxiliary means Like rubber ropes, as well as performing the jumping process by going down from a box with a calculated height and in a similar manner to the advancement process, but from standing up. The researcher notes that the average momentary push time for advancement with its development for the individuals in the research sample is somewhat large compared to I have achieved what has been achieved and which is supposed to be a lack of this time to achieve clear and rapid preparation. Because the increase in the momentary propulsion time the hopper needs at higher altitudes to convert the horizontal speed vehicle into a vertical vehicle, as Heinz and Powersfield emphasized that "the more a somewhat large angle of departure must be achieved the longer the advancement process occurs, and more clearly appears in the advancement movement to accomplish the required lift movement."

- The results showed the effectiveness of using exercises related to the skillful performance of the forward anterior airway movement.

- The special exercises have proven effective in developing and controlling force when getting up to perform the straight forward airway. 
- The use of (auxiliary method) has proven to be effective in giving the appropriate value to the force and on the basis of which the correct kinetic path is determined.

\section{ENDORSEMENT:}

The researcher recommends the following:

- Adopting modern techniques when analyzing a specific skill in gymnastics objectively to reveal strengths and weaknesses.

- Adopting special exercises according to some of the researched biomechanical variables to teach the skills of the straight forward airway.

- Adopting the skillful exercises to develop the physical side.

\section{Annex (1)}

Experts names

\section{REFERENCES:}

- Karl Heinz, Powersfield et al. (Translation) Qasim Hassan Hussein and AtheerSabri. Biomechanics.

- Attiyat Muhammad Khattab (and others). The Basics of Exercise and Rhythmic Exercises, Cairo, The Book Publishing Center, 2006, p. 29.

- Emad Halif Jaber Al-Assami, Prof. Dr. Hamid Abdul Nabi Al-Fatawi, Use of Exercises (PNF) for the rehabilitation of the musculoskeletal of the shoulder joint and evaluate using the technique (EMG) in the category of applicants to lift the burden of special needs. International Journal of Research in Social Sciences and Humanities, 2249-4642, 2019, pg: 21-26

\begin{tabular}{|l|l|l|}
\hline Workplace & Jurisdiction & $\begin{array}{l}\text { The name of the expert and the } \\
\text { title }\end{array}$ \\
\hline $\begin{array}{l}\text { University of Baghdad-College } \\
\text { of Physical Education and } \\
\text { Sports Science }\end{array}$ & Training / Biomechanic & Prof. Dr. Sareeh Abdul Karim \\
\hline $\begin{array}{l}\text { University of Baghdad - College } \\
\text { of Physical Education and } \\
\text { Sports Science for Girls }\end{array}$ & Biomechanics / gymnastics & Prof. Dr. HodaShihabJarry \\
\hline $\begin{array}{l}\text { Al-Qadisiyah University - } \\
\text { College of Physical Education } \\
\text { and Sports Science }\end{array}$ & Biomechanic / volleyball & $\begin{array}{l}\text { Prof. Dr. Ahmed Abdel Amir } \\
\text { Shebar }\end{array}$ \\
\hline
\end{tabular}

